\title{
Using a Professional Learning Community Framework to Assist Early Field Experience Students as They Move from Teacher Candidate to Teacher
}

\author{
Curtis P. Nielsen, EdD \\ Assistant Professor, Department of Teaching \\ University of Northern Iowa \\ Amy K. Lockhart, EdD \\ Assistant Professor, Department of Teaching \\ University of Northern Iowa
}

\begin{abstract}
Collaboration is rapidly becoming sacrosanct in today's K-12 schools. A basis for these collaborative school experiences is the ability to share one's observations of classroom activities. The Professional Learning Community (PLC) framework described here is a pedagogically based process that provides opportunities for Early Field Experience students to share their field involvements. The discussions are born from the teacher candidates' experiential learning as they take part in a 25-hour field placement. Providing teacher candidates with weekly PLC opportunities for sharing, simultaneously, has assisted teacher candidates' dispositional and pedagogical decision making as they make the transition from student to teacher.

In today's 21st Century elementary school, teacher to teacher collaborative discussion of pedagogy is rapidly becoming a foundational standard for school improvement and "key facet of present-day contexts of teaching" to increase student achievement (Ronfelt et al., 2015). This standard is a change from the traditional teacher isolationist model where each teacher was assigned a class of students and through trial and error exclusively taught that class (Tichenor \& Tichenor, 2019, p. 54). EvansStout (1998) makes clear that independent, trial and error teaching and learning strategies conducted by teachers can be positive. However, Evans-Stout (1998) goes on to argue that, "a teacher alone should no longer bear the sole responsibility for a student's success for one entire school year" (p. 122). Collaboration between teachers in a school context can bring unique pedagogical content and experiential knowledge to professional conversations, which support and ultimately focus on improved student achievement (Goddard et al., 2007; Tichenor \& Tichenor, 2019). Additionally, DuFour et al. (2010) stated, "In fact, the very reason that teachers work together in teams and engage in collective inquiry is to serve as catalysts for action" (p. 12). Through formal and informal conversations, teachers discuss curricular observations, student needs, and other data points while collaboratively making decisions, which may directly impact their classrooms. These conversations can be guided by queries that seek answers to student actions or pedagogical related topics developed by school districts, schools, or teacher teams. Goddard et al. (2007) assert that teacher collaborations "provide valuable opportunities for teachers to learn to improve their instruction" (p. 881). These opportunities many times build collective self-efficacy. As an example, one school, in what Tishenor and Tishenor (2019) called, "The least
\end{abstract}


common collaboration practice" (p. 54), organized volunteer small groups of teacher teams to visit classrooms in the school and observe the host teacher's instruction. Following the classroom visit a debriefing session using a protocol for feedback was utilized. Based on Diane Sweeney's (2016) "Learning Labs" model these learning opportunities have been very well received by the faculty participating and have created some interschool collaborative connections that were not previously in place. When finished with the small group work, each participant was surveyed and asked what from the experience they would remember. One teacher commented, "Teacher efficacy. Planning and reflections becoming more habitual rather than one-time events". Another stated, "Leads to just embedding better practices daily, not just for special visits." And a third mentioned, "Teachers teach teachers! Sharing ideas makes us better teachers!" (Nielsen et al., 2018). Characteristics of "mutual trust, respect and support" between and among these colleagues have been brought out through this process (Bolam et al. 2005, p. 145; Marzano et al., 2016, p. 6).

The current contexts of many elementary schools promote teacher to teacher interaction and collaboration (Hall \& Hord, 2011; Leithwood \& Lewis, 2012). In the same way, it would be wise to introduce teacher candidates to this current reality of collaboration in schools (TeKippe, 2017). Through the utilization of the PLC process, teacher candidates, during their early field experience, are provided the opportunity to examine many facets of the teaching profession through guided communication.

This article documents a program used at a midwestern university that provides early field experience students completing a 25-hour field placement the opportunity to share their varied classroom involvements with each other while they matriculate through an early field experience. The centerpiece to this sharing opportunity is a directed PLC designed to encourage inter-teacher candidate sharing of classroom involvements. These students, in the initial stages of transitioning from student to teacher, are building their skills in many teaching areas, among them collaboration. However, there is scant or non-existent literature with regard to using a PLC framework with early field experience teacher candidates.

While the foundation of this article is based in an elementary school, the authors believe the concepts discussed here are not limited to elementary school or educational contexts in general. These concepts and processes could also be impactful in the areas of health care and business. In these important areas of society "innovative thinking and risk-taking" are two essential components of transformation and collaboration (Palatta, 2018, p. 550). Additionally, Jacobs and Yendol-Hoppey (2010) claim discussions with others in their learning communities could foster deeper levels of learning and can move PLC members to action (p. 112). Given these findings, the authors consider it reasonable that the components and processes discussed in this article could be transferred to contexts outside of the realm of education.

\section{Literature Review}

The literature discussed here includes PLC research focused on schools' desire to be places of continuous improvement. Similarly, as teacher candidates continue to learn about teaching during their early field experiences, they too are looking for continuous improvement. The intention of this literature review is to 
provide some background regarding the definition of PLC, characteristics of a PLC, and the impact of positivity and social trust on the culture of a PLC.

\section{PLC Definition}

Defining PLCs has proven to be somewhat difficult as there are many interpretations (Voelkel \& Chrispeels, 2017). However, one could say a foundation of the PLC is a focus on looking for ways to continuously improve (Stoll et al., 2006; Voelkel \& Chrispeels, 2017). A teacher's continuous improvement is a key to student success in school (Carpenter, 2015; TeKippe, 2017). When teachers converse about student learning, professional development or the school organization, there can be an important impact for the school (Seashore et al., 2003). The PLC as a relational activity builds on an underpinning of interpersonal caring from the teacher, students and school administration (Hargreaves \& Giles, 2003; Louis et al., 1995). DuFour and Eaker (1998) define PLC by dissecting each word in the phrase. They mention that a professional is someone with expertise. Learning is "to study" and "to practice constantly," and the community they describe with a quote from McLaughlin and Davidson (1994):

Community means different things to different people. To some it is a safe haven where survival is assured through mutual cooperation. To others, it is a place of emotional support, with deep sharing and bonding with close friends. Some see community as an intense crucible for personal growth. For others, it is simply a place to pioneer their dreams. (DuFour \& Eaker, 1998, p. xii)

Whatever definition one ascribes, the PLC can be seen as a catalyst for change in the school as well as an avenue for collective efficacy among teachers (Voelkel \& Chrispeels, 2017). In the same way, teacher candidates can build collective efficacy through opportunities to communicate about their varied field experiences (TeKippe, 2017).

\section{Characteristics}

There appear to be several characteristics of PLCs. Stoll et. al (2006) claims there are five characteristics of effective PLCs:

- Shared values and vision

- Collective responsibility

- Reflective professional inquiry

- Collaboration

- Group, as well as individual, learning is promoted (p. 226-227)

As Stoll et al. (2006) work highlights the five key characteristics mentioned above, Bolam et al. (2005) also included characteristics of:

- Openness, networks, and partnerships

- Inclusive membership

- Mutual trust, respect, and support (p. 145) 
The ultimate impact is PLCs benefit to students' learning. PLCs are the vehicle by which teachers can learn from each other to improve their practice and ultimately meet the goal of increased student learning (Stoll et al., 2006). Effectiveness is central to the impact PLCs have on the school community. An effective PLC can enhance student learning by providing learning opportunities for all school community professionals (Bolam et al., 2005). When the characteristics of PLCs (Stoll et al., 2006; Bolam et al., 2005) are put into practice the benefit directly impacts success in school for students.

\section{Culture within PLC}

To enhance discussions and collaboration, Louis et al. (1995) and Nias et al. (1989) mention a culture of positivity in relationships and collegiality are important in schools that desire to work productively. This thought connects with the findings of Bolam et al.'s (2005) characteristics of openness, networks, and partnership. Bryk et al. (1999) mention that social trust is the most important factor to connect faculty members of a school in a PLC. Social trust and its resources "support collaboration, reflective dialogue, and deprivatization, characteristics of professional community" (p. 767). DuFour et al. (2010) claim that teachers work together to enhance the process and keep the process going, serving "as a catalyst for action" (p. 12). However, DuFour et al. (2010) also mention that in order to move a PLC forward a teacher should focus on themselves. Instead of looking at what others could do to improve the school, they should look inward, at themselves, as the influence they have could not only impact individual students but it could also have a wider impact on the school (p. 53). Tichenor and Tichenor (2019) supported DuFour et al.'s claim by stating, "Teacher collaboration is an essential component of effective schools" (p. 55). Also, Carpenter (2015) posits that effective collaboration is built on a foundation of respect for "skills, knowledge and experiences" through valued contributions in a school (p. 684). Finally, a culture of self-efficacy and optimism in PLCs will go a long way to building teacher collective efficacy by focusing on what is within each teacher in the PLC (Golman et al., 2002).

\section{Central Outcome of the Early Field Experience}

This early field experience provides each teacher candidate with a view of the teaching profession and is designed as a point of decision regarding his or her future as a teacher. During the Early Field Experience Professional Learning Community, a degree of professional maturation can occur in the teacher candidate, which signals the transition from teacher candidate to teacher. In one of the first theories of teacher development, the Developmental Teacher Concerns Model, Fuller (1969) identifies three developmental stages: (1) covert concerns about self; (2) overt concerns about self: and (3) concern about students (van der Lans et al., 2018, pp. 248-249; Wilkins et al., 2009, p. 82). Fuller (1969) found teacher candidates focused on themselves at the beginning of the clinical experience, and by the end, their focus had transitioned to the students (Snead \& Freiberg, 2019). Through active involvement in all areas of the early field experiences, but especially through their active involvement and engagement in this unique PLC, teacher candidates are afforded opportunities to learn from each other as they tangibly progress through this early field experience as Fuller (1969) described.

InSight: A Journal of Scholarly Teaching 


\section{Context}

The Early Field Experience Professional Learning Community (EFEPLC) framework took place at a medium-sized midwestern university of approximately 13,000 students. It is located in a metropolitan area, which includes about 115,000 residents. The university routinely graduates $500+$ students a year into the ranks of the teaching profession. The large majority $(83 \%)$ of students at this university are white and come from middle-class families within the midwestern United States. Approximately $90 \%$ of the students come from the state in which the university resides.

Prior to their formal, full semester of student teaching, each teacher candidate is required to complete $80+$ hours of practicum experiences with a classroom teacher who holds a state-issued permanent teaching license. Many times, these experiences are in community public school districts that are in close proximity to the university. During the field experience, each elementary teacher candidate, usually a sophomore, completes an eight-week course titled Teacher as a Change Agent. The first week of this course is an on-campus seminar. The next six-weeks constitutes a 25-hour field experience in a local elementary school. Finally, week eight has teacher candidates back on campus to reflect, like PLCs, on the field experience. This course is taken in concert with foundational courses in educational psychology and classroom assessment. As the second of four required experiences and completed prior to taking specific methodology courses associated with any major teaching field, each teacher candidate registers for a Monday, Wednesday, Friday one-hour fifty-minute or a Tuesday, Thursday two-hour fifty-minute section of the field experience course. This allows for the teacher candidate's field experience time to be captured in their schedule.

To facilitate and supervise this experience, a Field Experience Coordinator (FEC) is assigned to the elementary school by the university. The FEC is a licensed elementary teacher who holds a Doctorate in education and is employed full time by the university. The FEC is charged with several tasks during the eight-week course. During the first week of the course, they conduct a weeklong seminar, where teacher candidates are introduced to a variety of classroom pedagogical topics such as classroom management, motivation, instructional strategies, lesson planning, observation, and building positive relationships with students. These FEC professors recognize the complex nature of teaching. Therefore, there is no attempt during the seminar to do more than introduce these relevant elements of pedagogy to make teacher candidates aware of what topics will be further discussed during their teacher education coursework.

Second, FECs make daily visits to the school to work with the teacher candidates in their mentor teacher's classroom. During these observational meetings, one-on-one conversations take place regarding weekly focus topics (see Appendix) that the teacher candidate has observed.

Finally, the FECs organize and facilitate the weekly 30-minute EFEPLC meetings. These meetings are comprised of teacher candidates registered for either the Monday, Wednesday, and Friday session or Tuesday and Thursday session and convene at the placement school during the field experience time. There are six to eight teacher candidates in each group. The Appendix includes the assignment handout which explains each point of discussion for the EFEPLC sessions. 


\section{EFEPLC Process}

Professional Learning Communities are actively functioning in many publicschool districts today. Given this current trend, it would seem appropriate to introduce and prepare the teacher candidate for an environment of experiential sharing (TeKippe, 2017). The EFEPLC process for teacher candidates introduces the teacher candidate to an environment of pedagogical and observational sharing as well as to facilitate communication between and among teacher candidates as they have differentiated experiences. Specifically, this process offers an opportunity for teacher candidates to share experiences, discuss focused observations at differing grade levels and acquire lesson plan feedback from peers. This is characterized by Stoll et al. (2006) as "reflective professional inquiry" (p. 226).

The EFEPLC is designed to give teacher candidates the opportunity to systematically reflect and debrief their individual classroom experiences through the five elements of collaboration, conversation, presentation, common weekly theme discussion and inquiry-based questions that arise from classroom experiences (see Figure 1).

Figure 1

Early Field Experience Professional Learning Community Framework

EFEPLC CONSTANTS

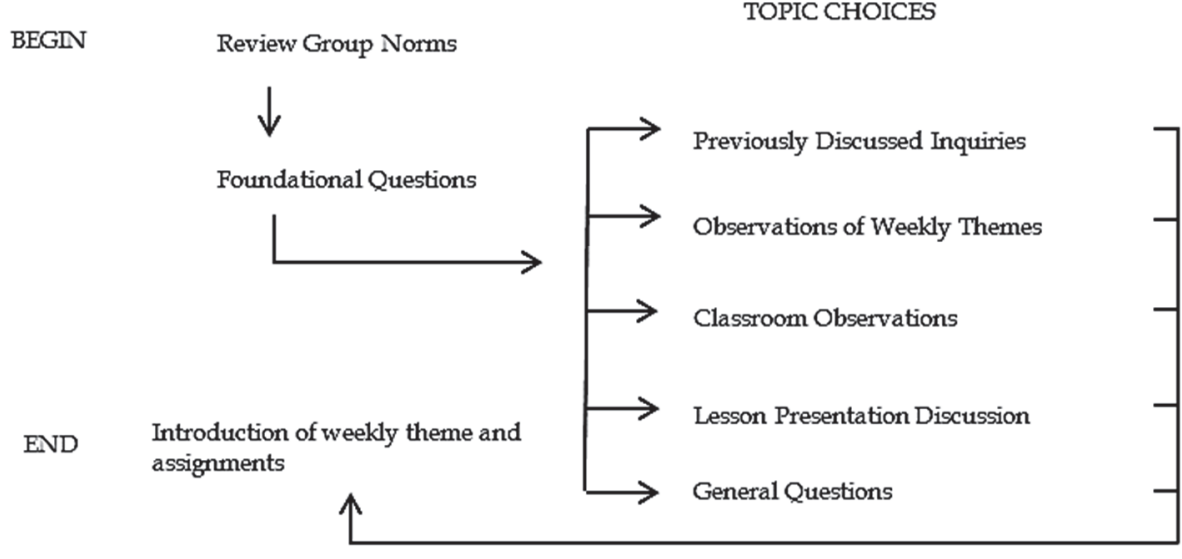

Figure 1 represents the general flow of the class meetings. All sessions begin with a review of the group norms, their "collective responsibilities", before moving on to the foundational question (Stoll et al., 2006) Given the diverse contexts of teacher candidate classroom assignments the following foundational questions are reviewed during each EFEPLC session:

- Why are we at this school?

- What work do we have to do?

- What inquiry questions are important to teacher candidates? 
After a review of the foundational questions, the teacher candidates promote their own learning by driving the discussion toward topics that meet their needs. These discussions frequently exhibit characteristics of collaboration through the teacher candidate feedback during the EFEPLC. A teacher candidate might comment on another's experience as similar to their own with the commenting teacher candidate providing affirming feedback or ask a question for further clarification. As seen in Figure 1 some of these other discussion topics include previously discussed inquiry questions, observation of weekly themes, classroom observation, discussion of the next themed observation and any assignments. At the end of the session, a focus topic is provided for the next week's field experience. Through this discussion phase, teacher candidates are able to come together as a group to communicate what is important to them in reference to their learning about teaching.

\section{EFEPLC Objectives}

There are two main objectives of the Early Field Experience Professional Learning Community endeavor.

\section{Objective 1}

Through weekly theme observations, teacher candidates will use an inquiry approach to learn about their classroom and school (the current reality), connecting their previous school experiences with the current reality to prepare them to teach their lessons.

The discussion questions (see Table 1) come from three basic themes: classroom management, instructional strategies and motivation/questioning. Each of these themes can be pedagogically intertwined for the veteran teacher in their reflections. However, for teacher candidates viewing their mentor teacher's classroom from a new perspective, that of a licensed teacher can create pedagogical misconceptions when discussing multiple themes. To add simplicity, themes are discussed weekly based on the teacher candidates' individual-focused observations. Sharing the observations with other teacher candidates can lead to a more fully formed pedagogical perspectives. These communications are an attempt to open up for the teacher candidate new pedagogical avenues of thinking.

Table 1

Discussion Questions - Focus of Weekly EFEPLC Meetings

\section{Classroom Management}

Through your experiences as a student in elementary, middle or high school, describe a classroom management technique that a teacher used (don't worry about the name of the technique, just describe it). Compare that experience with a technique you have observed in your Level II field experience. How would you feel about the management techniques as a student? Now, if you were a teacher would you use the same techniques? Why or why not? 
Table 1 Cont.

\section{Motivation/Questioning}

Looking back on your education, what learning strategies or questioning techniques did teachers use to motivate student learning? Explain. Would those techniques be effective in your Level II field experience classroom today? Why or why not.

\section{Instructional Strategies}

Think back to when you were an elementary student. Describe the most memorable experience you had as a learner. Describe the instructional strategy the teacher used to make the experience and learning come to life for you. Would that instructional strategy work in your Level II classroom and how would you use it there?

\section{Classroom Management}

How does the physical arrangement of the classroom impact management? How do you think adapting student assignments (for those with learning disabilities or those who need enrichment) has an impact on classroom management? How has your Mentor teacher adapted student assignments to meet classroom management needs?

In an attempt to attach new learning to the teacher candidates pre-existing schema, the discussion questions are formatted with these framing inquiries in mind:

- What are your previous experiences?

- What are you observing in your current field experience classrooms?

- Would your previous experienced techniques or strategies work in your current mentor teacher's classroom?

Each teacher candidate sharing previous personal educational experiences with the group can expose all teacher candidates to many different teaching experiences. This process can provide the teacher candidates with multiple

lenses from which to view their mentor teacher's classroom. Grossman and Davis (2012) posit that it takes classroom experience and time to fully understand the complexities of teaching. The period of time a student is in their teacher education matriculation is not enough time to fully grasp all of the intricacies of instruction ( $p$. 55). Given Grossman and Davis' (2012) claim one could conclude that teacher candidates learning from other teacher candidates' experiences may provide added experiential knowledge to bolster teacher candidates' future pedagogical readiness.

The PLC discussion and observation format were instrumental in allowing teacher candidates to communicate with each other and view each other's experiences both previous to and during the field experience with clarity. More in-depth research should take place to adequately study the discussion format used in this early field experience regarding its effectiveness. 


\section{Objective 2}

To cultivate the teacher candidate's transformation from student to teacher as they share their classroom involvements and instructional lessons they have written through this early field experience phase of the teacher education program.

The transition from student to teacher can be complicated. To simplify this transition, the nucleus of the early field experience is lesson planning. The Embedded Signature Assessment for Lesson Planning (ESA-LP) is a template-based format of four tasks where the teacher candidate ultimately plans and teaches two lessons. The pedagogical underpinning of this template is the gradual release of responsibility model. Fisher (2008) describes this model as moving the responsibility of performance from the teacher to the student through a gradually released process. The gradual release of responsibility methodology as seen in the lesson plan template requires each teacher candidate to complete four tasks. Task 1 invites the teacher candidate to work with the field coordinator and other teacher candidates as they critique a completed lesson plan template. Task 2 asks teacher candidates to begin looking at data from their placement school with other teacher candidates who are assigned to classrooms in the same school. During this task, the teacher candidate will also consult with their mentor teacher to more fully understand the demographics of the classroom. To complete Task 3, students will plan and deliver a lesson in their placement classroom with the assistance of the mentor teacher and field coordinator. Finally, in Task 4, students will create a lesson plan independently and turn that plan in for assessment and review by the FEC. Once modifications are made, they then teach that lesson to their placement classroom students. Through this gradual release process, the teacher candidates will collaborate with other teacher candidates, collaborate closely with their mentor teacher and field coordinator and attempt independent lesson planning and teaching. The gradual release methodology used here allows each teacher candidate to have multiple collaborative experiences.

As teacher candidates are progressing through the field experiences described above, they participate in the weekly EFEPLC processes. Their participation in both the field experience and the weekly meetings simultaneously affords each teacher candidate the opportunity for rich contemplation.

In addition to the weekly process as illustrated in Figure, 1 the framework of the six-week EFEPLC is displayed in Weeks 2 through 7 of the Appendix. These meetings are tightly connected to the weekly theme topics of classroom management, instructional strategies, and motivation/questioning. Through these topics, the teacher candidates focus their attention and direct their comments to more fully understand the context in which they as well as other teacher candidates are experiencing. These topics serve as underpinnings to the purpose of each of these meetings. The Appendix also houses specific tasks to be completed each week.

\section{From Student to Teacher}

In the past, without a concentrated focus provided by the EFEPLC questions, it was easy for teacher candidates to solely view themselves as students throughout the 
early field experience. In order to situate the change process from student to teacher in front of the teacher candidate, a foundational question was posed during the first meeting. The question, "Why are we at this school?" was put on chart paper and teacher candidate comments were recorded (DuFour et al., 2010). Through eight PLC groups, a pattern developed in the discussions of why the teacher candidates are at the school. Students mentioned the following during their first week of this field experience:

- $\quad$ practicing what we have learned and apply those skills

- completing assignments

- learning classroom management and gain experience

- experiencing a different perspective in school

When asked for a second time during week four of the session why they were at the school, teacher candidates' responses appeared to change focus from student to more closely resemble teacher thinking. The following responses were stated frequently by students:

- to create a positive learning environment

- $\quad$ build positive relationships with [K-6] students

- $\quad$ instruct [K-6] students

- encourage [K-6] students

- $\quad$ make the school a better place

- $\quad$ build relationships

Stated another way, teacher candidate responses in week one seemed to have an inward focus, looking at themselves as students. Week four comments take on more of a K-6 student focus, looking at the specific teacher responsibilities they have taken on in the classroom. This discovery is very similar to what Fuller (1969) found nearly 50 years prior with student teachers. As stated earlier in her Developmental Teacher Concerns Model, Fuller (1969) describes three stages of development: (1) covert concerns about self; (2) overt concerns about self; and (3) concern about students (van der Lans et al., 2018, p 248-249; Wilkins et al., 2009, p. 82). A focus on themselves was prevalent at the beginning of the semester. Then toward the end of the semester, her research showed that student teachers were more concerned with the students (Snead \& Freiberg, 2019). Possibly through classroom field experience and themed focused discussion questions examined during the sessions, teacher candidate's views of themselves in the classroom have been reimaged toward that of a classroom teacher. With classroom management, motivation and instructional strategies as central themes of the discussion questions, teacher candidates may see a clearer picture of their future as an educator.

\section{Future Directions}

The next logical step of this inquiry at this institution is to interview or survey teacher candidates about their specific involvement in the EFEPLC sessions. Learning more about teacher candidates' views of their experience and how the experience has impacted their learning and view of themselves as a teacher would be an insight worth

InSight: A Journal of Scholarly Teaching 
studying. Additionally, to add rigor to the process, it might be advantageous to have teacher candidates video record their lessons and then share the recording with another EFEPLC member than as an outside of class assignment provide each other feedback. Then during the EFEPLC time, the two students could share their feedback conversations with the rest of the group. This process would seem to align with Stone and Heen's (2015) belief that feedback is rooted in the "observations of your giver" (p. 54). Providing good feedback requires one to understand the context, namely, in this case, the teacher candidates' field experience classrooms.

Notably, during small group field experience exit meetings when asked what were the positives of the early field experience, all groups mentioned the value of the EFEPLC meetings. Knowing other teacher candidates were completing the field experience at the same school at the same time and being able to share teaching ideas with teacher candidates regardless of grade-level placement was most often mentioned as benefits of these meetings. It would seem appropriate that a future study includes questions inquiring specifically about the impact of this special PLC process on the experiential learning of the early field experience teacher candidate. In addition, it could also be beneficial to track a cadre of students through the remainder of their teacher education program to determine the lasting impact of these weekly meetings on their teacher preparation.

Finally, it would be worthwhile to expand this research to other teacher education programs in the future. Gathering a cohort of institutions that would be able to facilitate the EFEPLC might yield interesting results.

\section{Conclusion}

The authors believe there is generalizability to this process that could be beneficial for other teacher education institutions. The questions that frame the meeting sessions (see Table 1, p. 5) could simply be the focus of the discussion with any group. The early field experience teacher candidates within a program would not have to all go to the same K-12 school for their field experience; they could be paired and exchange video recordings of their lessons, providing feedback to each other. This method could provide multiple opportunities for early field experience students to gain insights into differing school contexts.

The EFEPLC process has provided the authors with a glimpse that teacher candidates can transition their focus from student to teacher. Focused classroom observations discussed during PLC meetings and based on questions that include points of reflection for the teacher candidate may activate future professional decisionmaking. Through modifying the questions described here this process can flex with each teacher candidate as well as individual teacher education programs. EFEPLC can be a conduit to teacher candidate decision making as they move from student to teacher. 


\section{References}

Bolam, R., McMahon, A., Stoll, L., Goddard, Y. L., Goddard, R. D., \& Thomas, S., Wallace, M., Greenwood, A., Tschannen-Moran, M. (2007). A ... \& Smith, M. (2005). Creating and theoretical and empirical investigation of sustaining effective professional learning teacher collaboration for school communities. (Research Report 637). DfES improvement and student achievement in and University of Bristol.

Bryk, A., Camburn, E., \& Louis, K. S. (1999). Professional community in Chicago Elementary Schools: Facilitating factors and organizational consequences. Educational Administration Quarterly, 35(Supplement), 751-781.

Carpenter, D. (2015). School culture and leadership of professional communities. International Journal of Educational Management, 29(5), 682-694.

DuFour, R., \& Eaker, R. (1998). Professional communities at work: Best practices for enhancing student achievement. Solution Tree Press.

DuFour, R., DuFour, R., Eaker, R., \& Many, T. (2010). Learning by doing: A handbook for professional learning communities at work. Solution Tree.

Evans-Stout, K. (1998). Implications for collaborative instructional practice. In D. G. Pounder (Ed.), Restructuring schools for collaboration: Promises and pitfalls (pp. 121134). State University of New York Press.

Fisher, D. (2008). Effective use of the gradual release of responsibility model.

http://oldmoodle.kentisd.org/file.php/13 9/November_2_2012/School_Improveme nt/Effective_Use_Douglas_Fisher.pdf

Fuller, F. F. (1969). Concerns of teachers: A developmental conceptualization. American Educational Research Journal, 6, 207-226. https://doi/org/10.1080/0040584090277622 public elementary schools. Teachers College Record, 109(4), 877-896.

Golman, D., Boyatzis, R., \& McKee, A. (2002). Primal leadership: Learning to lead with emotional intelligence. Harvard Business School Press.

Grossman, P., \& Davis, E. (2012). Mentoring that fits. Educational Leadership, 69(8), 54-57.

Hall, G. E., \& Hord, S. M. (2011). Implementing change: Patterns, principles, and potholes. (4 $4^{\text {th }}$ ed.). Parson Education, Inc.

Hargreaves, A., \& Giles, C. (2003). The knowledge society school: An endangered entity. In A. Hargreaves (Ed.). Teaching in the knowledge society: Education in the age of insecurity. Open University Press.

Jacobs, J., \& Yendol-Hoppey, D. (2010). Supervisor transformation within a professional learning community. Teacher Education Quarterly, 37, 97-114.

Leithwood, K., \& Louis, K. S. (2012). Linking leadership to student learning. Jossey-Bass Publishing.

Louis, K. S., Kruse, S., \& Bryk, A. S. (1995). Professionalism and community: What is it and why is it important in urban schools? In K. S. Louis, S. Krause \& Associates (Eds.), Professionalism and community: Perspectives on reforming urban schools. Corwin. $\underline{8}$ 
Marzano, R. J., Heflebower, T., Hoegh, J. K., Warrick, P., \& Grift, G. (2016). Collaborative teams that transform schools: The next steps in plcs. Marzano Research.

McLaughlin, C., \& Davidson, G. (1994). Spiritual politics: Changing the world from the inside out. Ballantine Books.

Nias, J., Southworth, G., \& Yeomans, R. (1989). Staff relationships in the primary school: A study of organizational cultures. Cassell.

Nielsen, C. P., Bryant, R., \& Simpson, K. (2018) Teacher to teacher: Teacher perceptions of the experience [Unpublished raw data].

Palatta, A. (2018). Change management in dental education: A professional learning community. Journal of Dental Education, 82(6), 549-556.

Ronfelt, M., Farmer, S. O., McQueen, K., \& Grissom, J. A. (2015). Teacher collaboration in instructional teams and student achievement. American Educational Research Journal, 52(3), 475514.

https://doi.org/10.3102/0002831215585562

Seashore, K. R., Anderson, A. R., \& Riedel, E. (2003). Implementing arts for academic achievement: The impact of mental models, professional community and interdisciplinary teaming.

Snead, L. O., \& Freiberg, H. J. (2019). Rethinking student teacher feedback: Using a self-assessment resource with student teachers. Journal of Teacher Education 70(2), 155-168.

Stoll, L., Bolam, R., McMahon, A., Wallace, M., \& Thomas, S. (2006). Professional learning communities: A review of the literature. Journal of Educational Change 7, 221-258.
Stone, D., \& Heen, S. (2014) Thanks for the feedback: The science and art of receiving feedback well. Penguin Books.

Sweeney, D. (2016, September 7). A vision for supporting model classroom teachers in Iowa.

https://dianesweeney.com/vision-forsupporting-model-classroom-teachersiowa/

TeKippe, S. S. (2017). A roadmap to increase active learning: Reading methodology courses with problem based learning in professional learning communities. Journal of Higher Education Theory and Practice, 17(9), 118-129.

Tichenor, M., \& Tichenor, J. (2019). Collaboration in the elementary school: What do teachers think? Journal of Curriculum and Teaching, 8(2), 54-61.

van der Lans, R. M., van de Grift, W. J. C. M., \& van Veen, K. (2018). Developing an instrument for teacher feedback: Using the Rasch model to explore teachers' development of effective teaching strategies and behaviors. The Journal of Experimental Education, 86(2), 247-264.

Voelkel, R. H., \& Chrispeels, J. H. (2017). Understanding the link between professional learning communities and teacher collective efficacy. School

Effectiveness and School Improvement: An International Journal of Research, Policy and Practice, 28(4), 505-526.

Wilkins, E. A., Shin, E., \& Ainsworth, J. (2009). The effects of peer feedback practices with elementary education teacher candidates. Teacher Education Quarterly, 36(2), 79-93. 


\section{Appendix}

\section{General Course Schedule}

Light gray rows indicate Early Field Experience Professional Learning Communities activities.

\begin{tabular}{|c|c|}
\hline $\begin{array}{l}\text { Week of } \\
\text { TEACH } 128\end{array}$ & Lesson Plan / Schedule \\
\hline Week 1 & $\begin{array}{l}\text { On campus seminar } \\
\text { - School orientation } \\
\text { - } \quad \text { Develop group norms (Create chart) } \\
\text { - } \text { (Create chart) } \\
\text { - Q2 What work do we have to do? (Create Chart) } \\
\text { - (Shared Knowledge of Mission) }\end{array}$ \\
\hline Week 2 & $\begin{array}{l}\text { In classroom } \\
\text { - Focus: Context and processes of the classroom } \\
\text { - } \text { Student Assignments: } \\
\text { - Classroom observations and complete Task } 2 \text { of ESA - } \\
\text { Lesson Planning }\end{array}$ \\
\hline Week 3 & $\begin{array}{l}\text { Review responses to Q1, Q2 } \\
\text { Focus: Classroom Management } \\
\text { - Create a bank of inquiry-based questions to aid in the ESA - } \\
\text { Lesson Planning } \\
\text { - } \quad \text { (i.e. What Common Core Essential Concepts and Skills will I } \\
\text { teach?) } \\
\text { - Discussion: 1. Classroom Management (see Table 1) } \\
\text { - Student Assignments: } \\
\text { - Lesson ideas and dates. }\end{array}$ \\
\hline Week 4 & $\begin{array}{l}\text { Review responses to Q1, Q2 } \\
\text { Focus: Motivation/Questioning } \\
\text { - } \quad \text { Inquiry question list additions and review } \\
\text { - } \quad \text { Reveal lesson topics } \\
\text { - } \quad \text { Discussion: 2. Motivation/Questioning (see Table 1) } \\
\text { - } \quad \text { Student Assignments: } \\
\text { - } \quad \text { Begin Task } 3 \text { construction and dates finalized }\end{array}$ \\
\hline
\end{tabular}




\begin{tabular}{|c|c|}
\hline Week 5 & $\begin{array}{l}\text { Review responses to Q1, Q2 } \\
\text { Focus: Instructional Strategies } \\
\text { - } \quad \text { Discussion: } 3 \text {. Instructional Strategies (see Table 1) } \\
\text { - } \quad \text { Task } 3 \text { Lesson Review } \\
\text { - Inquiry questions review } \\
\text { - } \quad \text { Student Assignments: } \\
\text { - } \quad \text { Finalize Task } 3 \text { or } 4 \text { construction and delivery }\end{array}$ \\
\hline Week 6 & $\begin{array}{l}\text { Review responses to Q1, Q2 } \\
\text { Focus: Classroom Management } \\
\text { - Discussion: } 4 . \text { Classroom Management (see Table 1) } \\
\text { - Task } 3 \text { and } 4 \text { reflection and discussion } \\
\text { - } \quad \text { Student Assignments: } \\
\text { - } \quad \text { Lesson delivery }\end{array}$ \\
\hline Week 7 & $\begin{array}{l}\text { Review responses to Q1, Q2 } \\
\text { Focus: Instructional Strategies } \\
\text { - Discussion: Task } 4 \text { Lesson reflection and discussion. }\end{array}$ \\
\hline Week 8 & $\begin{array}{l}\text { - On campus experiential review } \\
\text { - } \quad+/ \Delta \text { What went well? What could be improved? }\end{array}$ \\
\hline
\end{tabular}

Dr. Curtis Nielsen has 31 years of teaching experience at the K-12 and university levels. He has supervised over 700 university teacher education students as they completed their required field experience. Dr. Nielsen has taught undergraduate courses for the University of Northern Iowa's Department of Teaching as well as multiple courses for the Department of Educational Psychology, Foundations and Leadership Studies. Dr. Nielsen is also part of the Leadership Team at Lincoln Elementary in Cedar Falls. This group sets the course for the school with regard to PLC and Professional Development for the year.

Dr. Amy Lockhart is currently employed at the University of Northern Iowa and is a faculty member of the College of Education's Department of Teaching. Over the last 28 years, Dr. Lockhart has taught elementary-aged students (PreK-6th grade) and has taught undergraduate teacher education students. She has supervised approximately 800 university teacher education students during their early field experience. 